\title{
O começo dos programas culinários na televisão: de Julia Child (EUA) a Ofélia Anunciato (Brasil) ${ }^{1}$
}

\author{
Zulmira NÓBREGA ${ }^{2}$ \\ Tatiana Ramalho BARBOSA ${ }^{3}$
}

\begin{abstract}
Resumo:
A exibição de programas culinários consta nas grades de programação das emissoras desde a implantação da televisão, na década de 1940 (EUA) e na década de 1950 (Brasil). Este artigo busca identificar as características dos programas culinários pioneiros nos dois países: A Cozinha Maravilhosa da Ofélia, apresentado por Ofélia Anunciato, e The French Chef, com Julia Child, além de traçar um histórico do formato na televisão. Para tanto, esta pesquisa apoia-se em autores como Freixa e Chaves (2017), Montanari (2008), Collins (2009), Araújo (2018), Fernández-Armesto (2004), Child, Bertholle e Beck (2011), entre outros, bem como em levantamento de programas culinários na televisão, em portais de internet e aplicativos. Os resultados demonstram que até os anos 1990 o gênero culinário era o carro-chefe dos programas femininos que tiveram grande sucesso na TV brasileira, além de apresentarem formato simples e clássico. Conclui-se que os programas culinários, na contemporaneidade, ainda registram grande audiência e são apresentados em diversos formatos, demonstrando sua versatilidade. Eles conquistaram o horário nobre dos canais de televisão, atraindo um público que os acompanha em outras plataformas como sites, blogs, aplicativos e na TV streaming, colaborando, desta forma, com a cultura da convergência dos meios de comunicação.
\end{abstract}

Palavras-chave: história da televisão; programas culinários; Julia Child; Ofélia Anunciato.

\section{The beginning of culinary programs on television: from Julia Child (USA) to Ofélia Anunciato (Brazil)}

\begin{abstract}
:
The presentation of culinary programs is included in the programming guide of the broadcasters since the implantation of the television, in the 1940s (USA) and 1950s (Brazil). This article seeks to identify the characteristics of the pioneering culinary programs in both countries: Cozinha Maravilhosa da Ofélia, presented by Ofélia Anunciato, and The French Chef, with Julia Child. Moreover, it traces a historical of the genre in the television. To this end, this research is supported by authors such as Freixa and Chaves (2008), Montanari (2008), Collins (2009), Araújo (2018), Fernández-Armesto (2004), Child, Bertholle and Beck (2011), among others, as well as a survey of culinary programs on television, internet portals and applications. The results demonstrate that until the 1990s the culinary genre was the flagship of the female programs that had great success on brazilian TV, while showing a simple and classic format. The conclusion shows that the culinary programs, in contemporary times, still have great audience and are presented in several formats, showing their versatility. They achieved prime
\end{abstract}

\footnotetext{
${ }^{1}$ Este artigo apresenta dados revisados e ampliados a partir de trabalho apresentado no GT História das Mídias Audiovisuais no $12^{\circ}$ Encontro Nacional de História da Mídia em junho de 2019, na Universidade Federal do Rio Grande do Norte (UFRN), em Natal/RN. ${ }^{2}$ Doutora em Cultura e Sociedade pela Universidade Federal da Bahia (UFBA), professora do Programa de Pós-Graduação em
Jornalismo da Universidade Federal da Paraíba (UFPB). E-mail: zulmiranobrega@ @ol.com.br.

${ }^{3}$ Mestranda em Jornalismo pela Universidade Federal da Paraíba (UFPB).E-mail: tatiramalho@hotmail.com.
} 
time on television channels drawing an audience that follows them on other platforms such as websites, blogs, applications, and TV streaming, thus collaborating with the culture of media convergence.

Keywords: history of television; culinary programs on television; Julia Child; Ofélia Anunciato.

\title{
El comienzo de los programas culinarios en televisión: de Julia Child (Estados Unidos) a Ofélia Anunciato (Brasil)
}

\begin{abstract}
Resumen:
La presentación de programas culinarios está incluida en la guía de programación de las emisoras desde la implantación de la televisión, en los años 1940 (EE.UU.) y 1950 (Brasil). Este artículo busca identificar las características de los programas culinarios pioneros en ambos países: Cozinha Maravilhosa da Ofélia, presentado por Ofélia Anunciato y The French Chef, con Julia Child, además de hacer un recorrido histórico sobre el género en el medio. Para ello, esta investigación cuenta con el apoyo de autores como Freixa y Chaves (2008), Montanari (2008), Collins (2009), Araújo (2018), Armesto (2004), Child, Bertholle y Beck (2011), entre otros, así como una encuesta de programas culinarios en televisión, portales de Internet y aplicaciones. Los resultados muestran que hasta la década de los 1990 el género culinario fue el buque insignia de los programas femeninos que tuvieron mucho éxito en la televisión brasileña, además de presentar un formato simple y clásico. La conclusión muestra que los programas culinarios, en la actualidad, aún registran gran audiencia y son presentados en varios formatos, demostrando su versatilidad. Lograron horario estelar en los canales de televisión atrayendo una audiencia que los sigue en otras plataformas como sitios web, blogs, aplicaciones y TV streaming, colaborando así con la cultura de la convergencia de medios.
\end{abstract}

Palabras clave: historia de la televisión; programas culinarios en televisión; Julia Child; Ofélia Anunciato.

\section{Introdução}

A tradição de se registrar receitas nos remete a Marcus Gavius Apicius, que viveu entre os anos de 25 a.C. e 37 d.C, foi cozinheiro do imperador Nero, na Roma antiga e escreveu, em latim, um compêndio de 468 receitas culinárias. Oito séculos depois, as referidas receitas foram achadas por monges e reunidas no que ficou conhecido como De Re Coquinaria, o primeiro livro de receitas que se tem conhecimento (FREIXA; CHAVES, 2017). O registro revela a longevidade e a importância do ato de compartilhar receitas culinárias entre os membros de uma sociedade. O costume atravessa os séculos e pode ser referenciado por meio dos cadernos onde as matriarcas, em geral, anotavam suas preparações gastronômicas, que eram passadas de geração em geração.

Com o surgimento dos meios de comunicação, a tradição da transmissão do saber culinário ganha novos contornos, passando a acontecer de forma exponencial, atravessando as fronteiras locais e familiares. No Brasil, em particular, o contexto de instauração dos primeiros meios de comunicação em massa encontra-se estreitamente relacionado à veiculação de receitas culinárias, de modo que tal formato marca a história dos veículos impressos e, posteriormente, 
dos radiofônicos (RICCO; VANUCCI, 2017). Na medida em que se observa que a gastronomia conquistou seu lugar também nas telas de TV, revistas, portais de notícias, blogs, aplicativos, etc., pode-se afirmar que os espaços de veiculação de receitas culinárias vêm crescendo e se transformando.

Dessa forma, o objetivo deste artigo é apresentar um histórico do formato de programas culinários e identificar as características dos programas culinários pioneiros, tanto nos Estados Unidos (The French Chef), como no Brasil (A Cozinha Maravilhosa da Ofélia), relatando fatos importantes e marcantes dessas produções, bem como de suas apresentadoras, verdadeiros símbolos do gênero culinário televisivo.

Com relação ao aparecimento de programas culinários na televisão brasileira, verificase que acontece logo no início das primeiras transmissões, na década de 1950, transferindo um modelo já existente nos programas de rádio, no qual se tinha a oportunidade de utilizar recursos próprios da oralidade e acrescentar o recurso das imagens em movimento proporcionado pelo veículo recém-inaugurado. Ainda a esse respeito, cabe ressaltar que a transformação experimentada pelos programas culinários radiofônicos brasileiros nessa transição para a linguagem televisiva ocorreu uma década após a consolidação do formato nos Estados Unidos da América, ocorrida em 1940 (RICCO; VANUCCI, 2017; COLLINS, 2009).

$\mathrm{Na}$ contemporaneidade, os programas culinários cresceram, conquistaram o horário nobre dos canais de televisão (abertos e pagos), em formatos internacionais, até mesmo de reality shows, conquistando um público fiel que os acompanha em variadas plataformas, como sites, blogs e aplicativos. Collins (2009) acredita que essa variedade de formatos prova, indubitavelmente, que os consumidores desse gênero desejam mais que simplesmente a instrução de receitas, como acontecia no passado.

O interesse nesse tipo de programação parece estar ligado às necessidades e instintos básicos do ser humano, visto que a comida é uma dimensão primordial da cultura, e a alimentação, uma ação social que promove a partilha e a harmonia entre as pessoas. Não por acaso, o início da civilização está relacionado com a procura dos alimentos, com os rituais e costumes de seu cultivo, com as formas de preparação e com o prazer de comer, instituindo as bases de relacionamentos e construindo a identidade dos núcleos (STANDAGE, 2010; MONTANARI, 2008). 


\section{A importância da gastronomia para os Estudos Culturais}

O conhecimento das teorias da comunicação serve para embasar uma postura crítica e analítica de todo jornalista. Nesse sentido, pode-se afirmar que uma das teorias relevantes para a área é a dos Estudos Culturais. Para Escosteguy (2017, p. 152), desde a fundação da área por Richard Hoggart, compõem o eixo principal de observação dos Estudos Culturais "as relações entre a cultura contemporânea e a sociedade, isto é, suas formas culturais, instituições e práticas culturais, assim como suas relações com a sociedade e as mudanças sociais”. Dessa forma, destaca-se a importância da análise da cultura para uma melhor compreensão da padronização de comportamentos e o consumo de textos e práticas culturais.

De igual maneira, Agger (1992) argumenta que, a partir dos textos introdutórios desse campo de estudo, percebe-se o conceito de cultura alinhado ao caráter plural, dinâmico e ativo dos sujeitos e sociedades envolvidos.

Primeiro: a cultura não é uma identidade monolítica ou homogênea, mas, ao contrário, manifesta-se de maneira diferenciada em qualquer formação social ou época histórica. Segundo: a cultura não significa simplesmente sabedoria recebida ou experiência passiva, mas um grande número de intervenções ativas [...] que podem tanto mudar a história quanto transmitir o passado (AGGER, 1992, p. 89).

Percebe-se, portanto, em tal concepção, a interpretação de que cultura, história e sociedade estão intrinsecamente ligadas. E é justamente a análise dessa correlação que torna possível refletir e compreender determinada sociedade. Outrossim, diversos autores (MONTANARI, 2008; FREIXA; CHAVES, 2017; CASCUDO, 2011) observam que, por meio da ciência do estudo dos alimentos, do estudo da gastronomia, podemos descrever a cultura de um povo, compreender atitudes sociais e comportamentais, bem como hábitos que evoluíram com o passar das gerações.

Nesse sentido, compreender a comensalidade reveste-se de relevância em vários aspectos, podendo ser "tão importante culturalmente quanto os museus, as festas, as danças e os templos religiosos" (FREIXA; CHAVES, 2017, p. 19). A comida, muito além de sua função 
principal, a de alimentar o corpo, permeia as sociedades, proporcionando direta ou indiretamente, consciente ou inconscientemente, conforto, prazer, paz e união.

A busca pela sobrevivência levou o homem pré-histórico de nômade a produtor de alimentos e domesticador de animais, inventando formas de melhorar o gosto de suas comidas, acrescentando ingredientes da natureza e aprimorando as técnicas de cocção, em busca do bemestar em grupo (FREIXA; CHAVES, 2017, p. 23). Percebemos o caráter primordial dos alimentos para uma análise da evolução da civilização humana, diretamente relacionada com a procura dos alimentos, com os rituais e costumes de seu cultivo, com as formas de preparação e com o prazer de comer, moldando a identidade de cada comunidade.

Os pesquisadores Freixa e Chaves (2017), Montanari (2008), Fernández-Armesto (2004) e Franco (1998) corroboram com a ideia de que o alimento se tornou cultura desde que o homem aprendeu formas de cozinhá-lo, transformando-o em comida, consumindo-o diferentemente da maneira pela qual foi provido pela natureza. Ao proporcionar a reunião do grupo, a própria utilização do fogo para a preparação do alimento acabou estreitando laços coletivos, favorecendo a comunicação entre povos diversos. Com efeito, Ramalho e Saunders (2000, p.12) afirmam que "o comer não satisfaz apenas a necessidade biológica, mas preenche também funções simbólicas e sociais”. Analogamente, Montanari (2008, p.14) reforça o vínculo entre a comida e cultura:

Comida é cultura quando consumida, porque o homem embora podendo comer de tudo, ou talvez justamente por isso, na verdade não come qualquer coisa, mas escolhe a própria comida, com critérios ligados tanto às dimensões econômicas e nutricionais do gesto quanto aos valores simbólicos de que sua própria comida se reveste.

De igual maneira, Standage (2010, p. 7) também salienta a especificidade e relevância da pesquisa em gastronomia para o campo cultural, pois "ao longo do tempo, os alimentos fizeram mais do que simplesmente proporcionar sustento; eles agiram como catalisadores da transformação e da organização social, da concorrência geopolítica, do desenvolvimento industrial, do conflito militar e da expansão econômica".

Conforme exposto, os estudos relacionando gastronomia e cultura encontram vasto embasamento na literatura. Além disso, há também perspectivas que unem alimentação à 
religiosidade, relação essa presente em grande parte das instituições religiosas, visto que rituais são realizados com alimentos simbólicos, sagrados ou até com a proibição deles, reafirmando identidades e manifestações de um povo. Podemos, ainda, encontrar nas mitologias grega e romana deuses representando a comida ou a bebida, a exemplo de Dionísio/Baco, simbolizado como o deus do vinho, e de Deméter/Ceres, deusa da nutrição, dos cereais, entre outros. Nas religiões cristãs, por conseguinte, dois momentos bíblicos são referências para a compreensão da relação entre alimento e religião: o pão transformado, tomado como corpo de Cristo, e o vinho, como o sangue de Cristo.

Os simbolismos alimentares relacionados à religião também estão presentes nos milagres de Cristo, na Santa Ceia e em diversas parábolas apresentadas ao longo do Livro Sagrado. De igual maneira, nas religiões de matriz africana há os ebós ou oferendas de alimentos, oferta também realizada em religiões asiáticas como a zen-budista, que em seus altares domiciliares oferecem arroz, uma fruta ou algum doce. Temos, então, a constituição da identidade de um fiel ou devoto, mediada e permeada por alimentos. Ressalta-se, por fim, que Carneiro (2003, p. 83) sentencia que "a alimentação assume assim a função de distinguir religiosamente os povos para os quais a dieta torna-se um assunto muito mais transcendente do que a mera satisfação do estômago".

A comida, portanto, ultrapassa o entendimento simplista de ser apenas uma prática ao longo da história da civilização, dedicada ao que se come ou é próprio para comer. Para além dessa conceituação, o ato de se alimentar encontra-se diretamente ligado às tradições, afeições, emoções, culturas e até às convicções religiosas daqueles que comem, os comensais.

Em outra perspectiva, Ballerini (2015, p.169) discorre acerca da gastronomia como marca identitária de determinadas sociedades, explicando que se trata de "uma das formas mais tradicionais de espelhamento cultural de um povo". O autor (2015, p. 169) indaga ainda: "como não associar a paella à cultura espanhola, a lasanha à cultura italiana, o sashimi à japonesa, o acarajé à brasileira, o bobotie à africana, entre tantos outros exemplos?”, reforçando o sentido natural de pertencimento evocado pelos alimentos na constituição da cultura de um povo.

Igualmente, autores como Carneiro (2005), Montanari (2008) e Ballerini (2015) retratam a comida como parte integrante da cultura, além de elemento essencial para a identidade humana, e a alimentação como uma ação social que promove a partilha e a harmonia 
entre as pessoas. "Comer não é um ato solitário ou autônomo do ser humano, ao contrário, é a origem da socialização, pois, nas formas coletivas de se obter a comida, a espécie humana desenvolveu utensílios culturais diversos" (CARNEIRO, 2005, p.1).

Assim, compreende-se a gastronomia como fenômeno cultural que deve ser estudado e abordado pelos meios de comunicação de massa. E sua evolução exige a construção de reportagens cada vez mais elaboradas, firmando o jornalismo gastronômico como uma especialidade significante para qualquer profissional que atue na área.

\section{A transição da cozinha para a sala de estar}

O primeiro tempero descoberto pelo ser humano foi o fogo, levando em consideração que o sabor da refeição está relacionado à temperatura no momento do consumo. Quando o homem percebeu a carne mais saborosa e mais fácil de mastigar ao aproximá-la do fogo, nasceu a cozinha (MONTANARI, 2008; FRANCO, 1998). Posteriormente, pouco a pouco, os demais insumos, materiais e equipamentos foram sendo desenvolvidos e incorporados na preparação das comidas. A etimologia da palavra cozinha indica justamente essa relação: "é o cozer, isto é, o preparo de alimentos pela ação do fogo ou do calor" (HOMEM, 2003, p. 125). A cozinha consiste, ainda, em um compartimento delimitado da habitação em que se preparam os alimentos, e sua presença também indica as ações desenvolvidas no local.

A cozinha moderna passou por incontáveis transformações e o preparo das refeições mediado por meios de comunicação tem colaborado com essas alterações. $\mathrm{O}$ ato de cozinhar conquistou novos espaços dentro dos lares. Nesse sentido, a mudança da cozinha para a sala de estar foi um processo natural, com o advento dos programas culinários, primeiramente por meio do rádio e, em seguida, da televisão.

Collins (2009) detalha que nos Estados Unidos, desde a década de 1920 havia programas de rádio que apresentavam receitas, sendo os primeiros e mais famosos o Housekeeper chat, com Aunt Sammy, e o Gold Medal Flour Home Service Talks, com Betty Crocker. Uma curiosidade sobre esses dois programas é que as apresentadoras eram personagens fictícias. Aunt Sammy era, na verdade, uma personagem criada pelo Departamento de Agricultura do governo americano, interpretada por dezenas de mulheres diferentes, a exemplo de Nan Dummont. Betty era Marjorie Husted, contratada pela empresa Washburn Crosby para assumir 
o papel de Crocker, identificada apenas muitos anos mais tarde. A diferença marcante estava na condução do programa: enquanto Aunt Sammy era a voz do governo na comunicação com os fazendeiros, Betty era uma mascote comercial (COLLINS, 2009).

Após o sucesso no rádio, com a implantação das emissoras de televisão, aconteceu a transferência dos programas culinários para as telas, desde o surgimento da televisão, no mundo e no Brasil. O rádio tornou o formato conhecido, de fácil e barata produção. Junto com essas facilidades havia o simbolismo da mesa, ou do próprio ato de alimentar-se, considerado historicamente como agregador de famílias e de amizades. Buscando conhecer e oferecer variedades de pratos para poderem compartilhar refeições domésticas, as pessoas encontraram nos programas culinários uma excelente opção de entretenimento e de compartilhamento familiar (RICCO; VANUCCI, 2017).

Collins (2009) assinala que, nos EUA, o primeiro programa exclusivamente culinário ${ }^{4}$ foi ao ar na televisão em 1946, apresentado por James Beard, sob o título I Love To Eat, executando receitas sofisticadas de pratos franceses e chineses. A grande referência do gênero nos Estados Unidos é Julia Child (COLLINS, 2009; ARAÚJO, 2018), com o programa The French Chef. Com a maior parte da sua produção em preto e branco, o programa contava com sólidos 30 minutos de uma combinação aparentemente estranha - uma mulher alta, com enormes braços, movimentos ruidosamente rápidos e uma voz incomparável - que, a despeito disso, acabaram fazendo da apresentadora um exemplo de sucesso da televisão e gastronomia americana.

Conforme explicam Ricco e Vannucci (2017), na década de 1950 poucas mulheres no Brasil trabalhavam fora de casa e, portanto, elas geralmente dedicavam suas tardes para atividades que lhes dessem prazer - ver televisão era uma delas. Logo, a certeza da plateia garantida foi o ingrediente principal para o surgimento das primeiras revistas femininas na TV, comandadas por apresentadoras que já faziam parte do cotidiano das telespectadoras, porque muitas atuavam como garotas-propaganda e, por isso, passavam credibilidade.

\footnotetext{
${ }^{4}$ Adotamos o termo "culinário" para nos referir a programas televisivos que aparecem sozinhos na programação dos canais, ou ainda que estejam inseridos dentro de outros programas de outros gêneros, conforme definição de Souza (2015).
} 
Observa-se que até a década de 1990 a culinária era o carro-chefe dos programas femininos que fizeram sucesso na TV brasileira. Segundo Araújo (2018), em sua primeira fase a televisão brasileira restringiu os primeiros programas culinários ao público feminino, exibindo os quadros no turno da tarde para atingir as donas de casa. Nessa época, os temas gastronômicos ocupavam blocos de conteúdos dentro de um programa específico. No Brasil, o programa televisivo Revista Feminina, exibido pela TV Tupi de São Paulo, notabilizou-se como o pioneiro no gênero. A esse respeito, Araújo (2018, p. 11) ressalta que o referido programa foi "o primeiro a abrir espaço para um quadro de culinária, sob a condução da culinarista Ofélia Anunciato, a qual permaneceu no posto entre 1958 e 1968 ".

A seguir, apresentamos a história do The French Chef, um programa de sucesso, com início na televisão pública americana que serviu de modelo para diversos outros que surgiram posteriormente. A figura caricata da apresentadora, Julia Child, atraiu a atenção dos telespectadores e acabou se tornando referência no gênero. O início da carreira de Julia, que se deu por conta de um curso que ela participou na França, bem como por seu amor à gastronomia, foi retratado pelo filme Julie \& Julia (2009), que rendeu a Meryl Streep, no papel de Child, uma indicação para o Oscar e Globo de Ouro de melhor atriz em 2010.

\section{The French Chef e o pioneirismo americano}

James Beard e Diane Lucas iniciaram as atividades de apresentadores de programas de culinária nos Estados Unidos. James Beard combinou instrução e diversão, mas seu programa, mesmo com entretenimento, durou menos de um ano no ar. Diane Lucas, com o programa intitulado To the Queens Taste, também teve pouca repercussão e durou menos que o de James Beard. De fato, o grande sucesso do formato ainda estava por aparecer, com Julia Child (COLLINS, 2009).

Julia Carolyn McWilliams (seu nome de solteira), nascida na Califórnia, "tornou-se" Child aos 34 anos, devido ao seu casamento com Paul Child, um funcionário do governo americano, em 1946. Os dois se mudaram para Paris, onde Julia se apaixonou pela cozinha francesa. Esse fato mudou sua vida e a de muitas cozinheiras americanas comuns "sem empregadas e que podem ficar, em algumas ocasiões, despreocupadas com orçamentos, cinturas, cronogramas, refeições dos filhos ou qualquer outra coisa que possa interferir no 
prazer de cozinhar alguma coisa maravilhosa para comer", 5 conforme ela própria descreveu no prefácio da edição original do seu livro Mastering the Art of French Cooking (CHILD; BERTHOLLE; BECK, 2011, p. vii, tradução nossa).

Da sua paixão pela cuisine française veio a decisão de se matricular em um curso de culinária no renomado instituto Le Cordon Bleu, onde enfrentou preconceitos por ser mulher e americana. Após o término do curso, Julia Child se dedicou a escrever o primeiro livro e a dar aulas às francesas, criando com Simone Beck e Louisette Bertholle a escola de culinária chamada Les 3 Gourmades (POWELL, 2006).

Voltando aos Estados Unidos, já aos 50 anos, Julia Child teve a oportunidade de filmar a preparação das receitas e exibi-las nas telas da TV, no programa que recebeu o título de The French Chef (Figura 1).

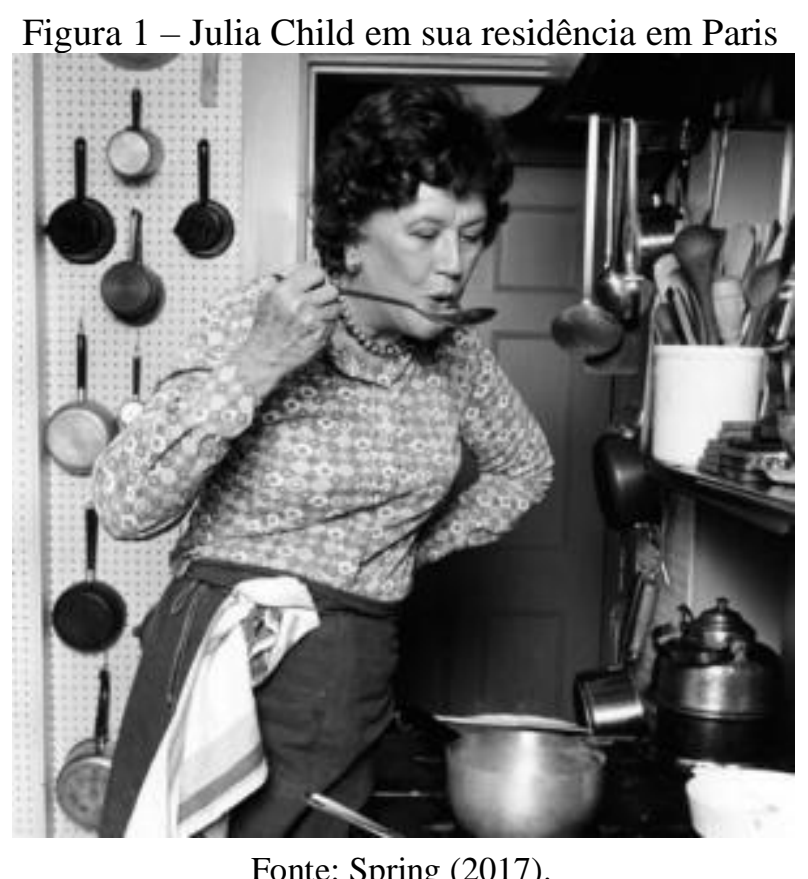

Ela não era francesa, nem se considerava chef (apesar do seu diploma pelo Le Cordon $\mathrm{Bleu}$ ), mas conseguiu revolucionar a gastronomia americana e, de certa forma, a TV daquele país - seu programa culinário é considerado o primeiro a ser exibido em um canal aberto de

\footnotetext{
${ }^{5}$ No original: "[...] for the servantless American cook who can be unconcerned on occasion with budgets, waistlines, time schedules, children's meals, or anything else which might interfere with the enjoyment of producing something wonderful to eat" (CHILD; BERTHOLLE; BECK, 2011, p. vii).
} 
TV. Os episódios-piloto de The French Chef foram produzidos pela televisão pública de Boston, a WGBH, e distribuídos nacionalmente pela rede de TV PBS (Public Broadcasting TV), entre 1963 e 1973 (COLLINS, 2009; ROSNER, 2019). As razões para a escolha do nome para o programa são explicadas pela própria apresentadora:

Por que $O$ Chef Francês se eu não sou nem uma coisa nem outra? A primeira razão foi que eu sempre quis que nós tivéssemos alguns chefs franceses de verdade nos programas. Algo que nós não conseguimos até mais tarde. $\mathrm{O}$ segundo e mais importante motivo: o título era curto, descrevia o programa como cozinha realmente francesa e, com igual significância, cabia em uma linha única nos guias de TV (CHILD; BERTHOLE; BECK, 2011, p. 18, tradução nossa). ${ }^{6}$

Durante os dez anos de exibição do programa The French Chef, Julia Child defendeu um jeito francês de cozinhar, acabou promovendo o consumo de vegetais, bons laticínios e ingredientes integrais, mudando os hábitos de consumir alimentos enlatados adquiridos pelos norte-americanos após a Segunda Guerra, assim como transformando o cansativo ritual de preparar e ingerir as refeições em uma atividade prazerosa (ROSNER, 2019).

A multitarefa Julia Child foi cozinheira, apresentadora de televisão, escritora e docente. Quando perguntada sobre com qual profissão mais se identificava, ela não hesitava em responder: "professora". Passou a ser, então, pioneira na reivindicação de transformar a gastronomia em campo de estudo universitário. No sentido de publicizar sua opinião, Child (2019, p. 66, tradução nossa) ponderou:

Uma pessoa pode ter um diploma em Artes, com habilitação em dança. Eu queria que as pessoas pudessem ter um diploma em Artes, com habilitação em gastronomia. Nós precisamos de pessoas que possam ser líderes na profissão, algo que não pode acontecer sem educação. ${ }^{7}$

\footnotetext{
${ }^{6}$ No original: "Why The French Chef, since I am neither the one nor the other? The first reason was that I always hoped we would have some real French chefs on the shows. We never managed that until later on. The second and more important reason: The title was short, it described the shows as real French cooking, and, of equal significance, it fit on a single line in the TV guides" (CHILD; BERTHOLE; BECK, 2011, p. 18).

${ }^{7}$ No original: "You can get a degree in fine arts- dance. I'd like for people to be able to go to the universities and get a degree in fine arts-gastronomy. What's needed are people who can be leaders in the profession, which can't be without an education" (CHILD, 2019, p. 66).
} 
Pouco antes de falecer, em 2004, Julia Child pôde vivenciar a revolução que a gastronomia provocou tanto nas telas da TV como nas universidades. Em 2010, aproximadamente 261 faculdades já ofereciam o diploma associado em gastronomia nos Estados Unidos (equivalente ao tecnólogo brasileiro). O primeiro bacharelado em Culinary Arts foi oferecido pelo Culinary Institute of America em 1993, tendo contado, inclusive, com patrocínio da própria Julia Child (CIA..., [2019]).

\section{A Cozinha Maravilhosa da Ofélia}

O primeiro programa culinário veiculado em um canal de TV aberta no Brasil foi $A$ Cozinha Maravilhosa da Ofélia, exibido pela TV Bandeirantes. Tendo permanecido nas telas por 30 anos, esse programa acabou fazendo com que sua apresentadora, Ofélia Ramos Anunciato, entrasse para a história da televisão brasileira (PAIVA, 2015; HOLZBACH, 2017; ARAÚJO, 2018).

A carreira de Ofélia, contudo, havia iniciado um pouco antes, no final da década de 1950, com sua atuação como colunista do jornal Tribuna de Santos, onde publicava suas receitas. A apresentadora conta que a oportunidade surgiu quando o avô do seu marido, que trabalhava para o jornal, comentou com seu chefe sobre os talentos de Ofélia na cozinha. Foi então que recebeu o convite para escrever uma coluna semanal, chamada Um docinho para mamãe, em 1958 (ARAÚJO, 2018).

No mesmo ano, Ofélia Anunciato estreia na televisão, na antiga TV Tupi de São Paulo, apresentando um quadro de receitas dentro do programa Revista Feminina, conforme descrevemos anteriormente. A apresentadora continuou ensinando receitas a donas de casa na emissora por dez anos, até 1968 (PAIVA, 2015; HOLZBACH, 2017; ARAÚJO, 2018).

Devido ao sucesso alcançado com o quadro culinário, Ofélia Anunciato é convidada pela TV Bandeirantes a estrelar um programa autônomo, exclusivamente dedicado à gastronomia. Assim, em 1968, a apresentadora estreia um dos programas mais longevos da televisão brasileira, A Cozinha Maravilhosa da Ofélia, que permaneceu no ar até 1998, ano de seu falecimento. A apresentação de receitas em televisão feita por Ofélia aconteceu durante 40 anos, no total (HOLZBACH, 2017; ARAUJO, 2018). 
Figura 2 - Ofélia apresentado A Cozinha Maravilhosa da Ofélia

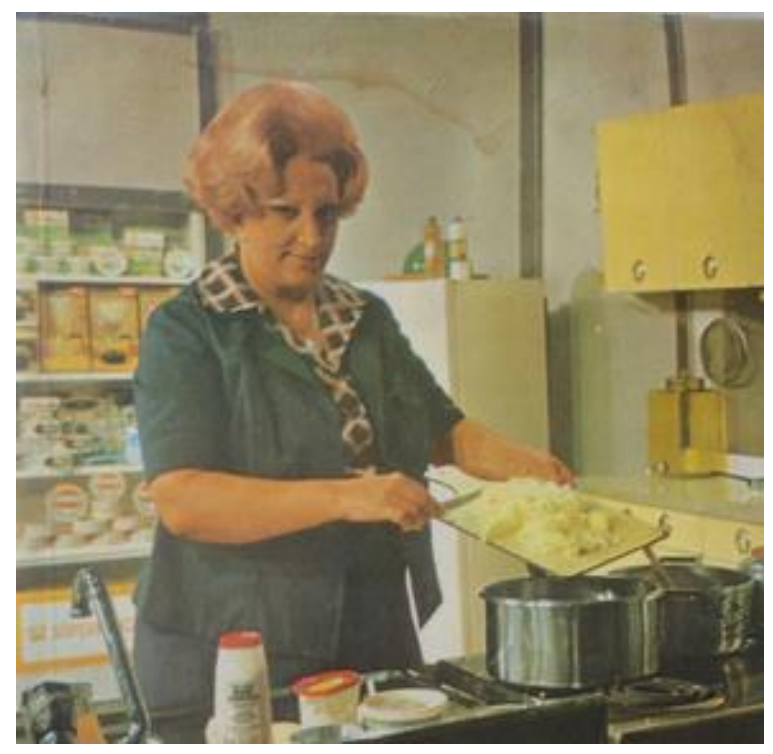

Fonte: Anunciato (1976).

O referido programa apresentava o preparo das comidas de forma didática, promovendo uma espécie de alfabetização gastronômica dos telespectadores, conseguindo manter sua característica instrucional do início ao fim com alto teor educativo, que objetivava ensinar especialmente o público feminino a cozinhar "bem” (HOLZBACH, 2017; ARAÚJO, 2018).

O formato técnico do programa seguia um padrão que a apresentadora tornou clássico. Ofélia Anunciato em primeiro plano, com um balcão servindo de mesa onde preparava os alimentos; em segundo plano uma cozinha moderna e bem equipada, transmitindo ao vivo, de segunda a sexta-feira, às 9h30. Mesmo sem contar com grandes inovações, a atração resistiu à concorrência de similares que surgiam e desapareciam em diferentes emissoras. Por bastante tempo, os outros programas culinários seguiram o modelo de Ofélia: "uma senhora sorridente dando o passo a passo da receita ao lado do fogão, para um público essencialmente feminino", conforme aponta Bueno (2016, p. 64).

Sobre a produção da atração televisiva de Ofélia, Araújo (2018, p. 12) também descreve suas características:

A produção de A Cozinha Maravilhosa da Ofélia quase nada recorria a elementos de entretenimento, quando muito exibia um bate-papo da culinarista com convidados, procurando, assim, manter o caráter instrucional 
do programa e o atendimento às demandas culinárias de seu típico público (ARAÚJO, 2018, p. 12).

Invariavelmente calma e demonstrando simpatia, Ofélia Anunciato conversava em tom de intimidade com as telespectadoras enquanto ensinava um novo prato a cada dia. No dia 26 de outubro de 1998 foi ao ar a última edição de seu programa A Cozinha Maravilhosa da Ofélia.

\section{Considerações finais}

Com a introdução das emissoras de televisão norte-americanas (década de 1940) e brasileiras (década de 1950), alguns formatos existentes nas rádios migraram para o novo veículo de comunicação. A partir de então, além de ouvir os seus programas favoritos, o público poderia também ver as imagens e em movimento. As atrações passaram a se adaptar à linguagem da mídia televisiva, quando os recursos próprios da oralidade (gestos e expressões) se juntaram às imagens, proporcionando uma experiência nova, mesmo que não tenha havido profundas alterações em seus formatos. Assim aconteceu com os programas culinários, presentes nas grades de programação das TVs desde a implantação do próprio meio.

Transcorridas décadas, a realidade dos programas culinários mudou significativamente, pois há uma explosão deles, com características e estruturas variadas. Julia Child e Ofélia Anunciato abriram as portas para que outros culinaristas invadissem a televisão, com os mais diversos estilos: da vovó Palmirinha Onofre à mesa "natureba" de Bela Gil, passando pelos galãs Dalton Rangel e Rodrigo Hilbert e culminando com os sotaques franceses de Claude Troisgros e Erick Jacquin.

No entanto, o estilo centralizado em um(a) cozinheiro(a) preparando comida diante de uma câmera ganha nova forma. Grande parte dos programas exibidos atualmente utiliza uma dinâmica baseada em competições que ocupam horários nobres da grade televisiva, como é o caso dos reality shows de comida, que surgiram, em sua fase inicial, nos canais de televisão por assinatura (BUENO, 2016; HOLZBACH, 2017).

Na TV aberta, o MasterChef Brasil, exibido pela Rede Bandeirantes desde 2014, é um dos reality shows de maior sucesso no país (HOLZBACH, 2017). O programa busca eleger o melhor cozinheiro amador entre competidores que devem realizar provas (desafios) cozinhando dentro de um tema proposto e com ingredientes previamente estabelecidos. A esse respeito, 
Holzbach (2017, p. 141) ressalta que para atrair a atenção do público e conceder um ritmo de disputa às provas, são utilizadas "pelo menos três estratégias que, encadeadas, geram um ambiente de tensão e expectativa: as preparações devem ser elaboradas em um tempo fixo, os jurados avaliam os pratos sem poupar críticas e os desafios incluem preparações feitas individualmente e em grupo".

Outro exemplo da importância do gênero no Brasil contemporâneo foi a criação de $O$ Mestre Do Sabor, primeiro reality show de comida exibido pela Rede Globo de Televisão, apresentado pelo chef francês Claude Troisgros e seu assistente Batista. Antes da estreia no canal aberto da TV Globo, Claude já havia comandado seis programas na GNT, pertencente ao mesmo grupo, entre eles os famosos The Taste Brasil e Que Marravilha! (PAIVA, 2015).

Ainda destacamos os quadros Super Chef (2012 a 2015) e Jogo de panelas (2012 atualidade), exibidos no programa Mais Você, apresentado por Ana Maria Braga - ambos também no formato de reality show, apresentando disputas decididas pelos telespectadores, que, por meio de votação pela internet, decidem quem deve continuar no programa (PAIVA, 2015).

Como exemplo da extraordinária ascensão do tema gastronomia, citamos a implantação do Chef TV, canal pago por assinatura, que entrou no ar no final de 2011 e se tornou o primeiro canal do país dedicado exclusivamente à gastronomia, com programação 24 horas, atingindo todo o território nacional, com sete milhões de telespectadores e " $80 \%$ de produção nacional e $20 \%$ da programação de culinária internacional" (SOBRE..., [2020]). O canal conta com 43 programas, tais como: 5 Sentidos, BBQ em Casa, Canapés e outras Geometrias, Diga Maria!, Do Mar ao Pomar, Chef, Folia na Cozinha, Gastrô, Mercados e Sabores do Mundo, Mesa Latina, Nosso Chef, Não Jogue Fora, Restaurantes de Charme, Sabor de Dendê, Sabores de São Paulo, VegetariRANGO, entre outros.

Seguindo a tendência de conteúdos multiplataforma, a programação do Chef $T V$ ainda pode ser acessada ao vivo no site, no YouTube e no app Chef TV Play. Cabe ressaltar que essa característica na distribuição do conteúdo do referido canal traz inovação ao formato. Trata-se da convergência quase obrigatória entre TV e Internet, pois grande parte dos telespectadores vê o programa nas telas e recorre aos sites para encontrar e fazer download das receitas exibidas.

Finalmente, conclui-se que os programas A Cozinha Maravilhosa da Ofélia, apresentado por Ofélia Anunciato no Brasil e The French Chef, sob o comando de Julia Child 
nos Estados Unidos, foram pioneiros no gênero televisivo dos programas culinários. Apesar de terem aspectos diferentes, ambos apresentavam formato simples, ambientados em cozinhas e exibidos em horários vespertinos ou matutinos para um público exclusivamente feminino, e ensinando, didaticamente, as donas de casa a prepararem os pratos do dia a dia da família. Com a evolução do próprio meio, além da transnacionalização dos formatos, o gênero se transformou, preservando, porém, o essencial: o registro e a transmissão de receitas.

\section{Referências}

AGGER, Ben. Cultural Studies as critical theory. London/Washington DC: The Falmer Press, 1992.

ANUNCIATO, Ofélia. A cozinha maravilhosa de Ofélia. São Paulo: Melhoramentos, 1976.

ARAÚJO, Amanda Tiemann. As panelas na telinha da TV: a cozinha maravilhosa da Ofélia, o culinário televisivo na década de 1980. In: ENCONTRO REGIONAL DA ANPUH-SÃO PAULO, 24., 2018, Guarulhos. Anais [...]. Guarulhos: UNIFESP, 2018. Disponível em: https://www.encontro2018.sp.anpuh.org/resources/anais/8/1533016459_ARQUIVO_Aspanel asnatelinhadaTV.pdf. Acesso em: 23 dez. 2020.

BALLERINI, Franthiesco. Jornalismo cultural no século 21: literatura, artes visuais, teatro, cinema e música: a história, as novas plataformas, o ensino e as tendências na prática. São Paulo: Summus, 2015.

BUENO, Chris. Febre Culinária. Ciência e Cultura, v. 68, n. 1, p. 63-65, jan./mar. 2016. Disponível em: http://dx.doi.org/10.21800/2317-66602016000100020. Acesso em: 26 dez. 2020.

CARNEIRO, Henrique. Comida e sociedade: uma história da alimentação. Rio de Janeiro: Elsevier, 2003.

CARNEIRO, Henrique S. Comida e sociedade: significados sociais na história da alimentação. História: Questões \& Debates, Curitiba, v. 42, n. 1, p. 71-80, jan./jun. 2005. Disponível em: https://revistas.ufpr.br/historia/article/view/4640/3800. Acesso em: 18 maio 2019.

CASCUDO, Luis da Câmara. História da alimentação no Brasil. São Paulo: Global, 2011.

CHILD, Julia. The last interview and other conversations. New York: Melville House Publishing, 2019. 
CHILD, Julia; BERTHOLLE, Louisette; BECK, Simone. Mastering the art of french cooking. New York: Alfred A. Knopf, 2011.

CIA history: a legacy of excellence, professional advancement, and innovation. The Culinary Institute of America. New York, [2019]. Disponível em: https://www.ciachef.edu/our-story/. Acesso em: 10 jul. 2019.

COLLINS, Kathleen. Watching what we eat: the evolution of television cooking shows. New York: Continuum, 2009.

ESCOSTEGUY, Ana Carolina. Os estudos culturais. In: HOHLFELDT, Antonio; MARTINO, Luiz C.; FRANÇA, Vera Veiga (org.) Teorias da Comunicação: conceitos, escolas e tendências. 15. ed. Petrópolis: Vozes, 2017. p. 151-170.

FERNÁNDEZ-ARMESTO, Felipe. Comida: uma história. Rio de Janeiro: Record, 2004.

FRANCO, Ariovaldo. De caçador a gourmet: uma história da gastronomia. São Paulo: Estação Liberdade, 1998.

FREIXA, Dolores; CHAVES, Guta. Gastronomia no Brasil e no mundo. Rio de Janeiro: Senac, 2017.

HOLZBACH, Ariane Diniz. A comida como chef de um formato televisivo: MasterChef Brasil versus MasterChef Colômbia. Comunicação, Mídia e Consumo, São Paulo, v. 14, n. 39, p. 131-151, jan./abr. 2017. Disponível em: http://dx.doi.org/10.18568/cmc.v14i39.1241. Acesso em: 01 maio 2019.

HOMEM, Maria Cecília Naclério. Princípio da racionalidade e a gênese da cozinha moderna. Pós. Revista do Programa de Pós-Graduação em Arquitetura e Urbanismo da FAUUSP, São Paulo, n. 13, p. 124-154, jun. 2003. Disponível em: https://doi.org/10.11606/issn.23172762.v13i0p124-154. Acesso em: 20 dez. 2020.

MONTANARI, Massimo. Comida como cultura. São Paulo: Editora Senac, 2008.

PAIVA, Raquel Sabatovicz. Culinária na TV brasileira: uma receita que nunca perde o ponto. 2015. Trabalho de Conclusão de Curso (Graduação em Comunicação Organizacional) Universidade de Brasília, Brasília, 2015. Disponível em: https://bdm.unb.br/handle/10483/12139._Acesso em: 20 mar. 2020.

POWELL, Julie. Julie and Julia: my year of cooking dangerously. New York: Back Bay Books, 2006.

RAMALHO, Rejane Andréa; SAUNDERS, Cláudia. O papel da educação nutricional no combate às carências nutricionais. Revista de Nutrição, Campinas, v. 13, n. 1, p. 11-16, 
jan./abr. 2000. Disponível em: https://www.scielo.br/scielo.php?pid=S141552732000000100002\&script=sci_abstract\&tlng=pt. Acesso em: 05 maio 2019.

RICCO, Flávio; VANNUCCI, José Armando. Biografia da televisão brasileira. São Paulo: Matrix, 2017.

ROSNER, Hellen. Introduction. In: CHILD, Julia. The last interview and other conversations. New York: Melville House Publishing, 2019. p. 7-16.

SOBRE nós. Chef TV, [São Paulo], [2020]. Disponível em: http://www.cheftv.com.br/sobrenos/. Acesso em: 09 jul. 2020.

SOUZA, José Carlos Aronchi de. Gêneros e formatos na televisão brasileira. São Paulo: Summus. 2005.

SPRING, Kelly A. Julia Child (1912-2004). In: National Women's History Museum. [Washington, DC], 2017. Disponível em: https://www.womenshistory.org/educationresources/biographies/julia-child. Acesso em: 23 dez. 2020.

STANDAGE, Tom. Uma história comestível da humanidade. Rio de Janeiro: Jorge Zahar Ed., 2010.

Submetido em: 12.04.2020.

Aprovado em: 31.12.2020. 